\title{
EL SER COINCIDENTAL EN LA ÉTICA DE ARISTÓTELES
}

\author{
Alejandro Llano \\ Universidad de Navarra, España \\ allano@unav.es
}

\begin{abstract}
Aristotle's ethics combines the consideration of need (from the moral law and interned by virtues) with coincidences and accidents of chance. Fortune and misfortune are key elements to the deploy of human condition, as may be appreciated in Greek tragedy. So, the plurality of human senses is translated to the philosophic scope. The coincidental being is the most relevant sense for ethics, because man is not everything he can be. This states the main issue as of, if accomplishing happiness depends on us or if it is conditioned by chance and fortune. Aristotle sustains that it is absolutely necessary to keep in mind the presence of chance factors as well. The contribution of Poetics is very relevant to the matter.
\end{abstract}

Key words: Ethics, chance, casuality, coincidental being, moral fault, virtue, happiness, Aristotle.

\section{Resumen}

La ética aristotélica combina la consideración de la necesidad proveniente de la ley moral e internalizadada por las virtudes con las coincidencias y accidentes que provienen del azar. La fortuna y el infortunio son factores clave en el despliegue de la condición humana, según se aprecia en la tragedia griega. Se traduce así al ámbito de la filosofía práctica la pluralidad de los sentidos del ser. El ser coincidental es el sentido más relevante para la ética, porque el hombre no es todo lo que puede ser. Esto plantea el problema central de si el logro de la felicidad depende de nosotros o está condicionado por el azar y la fortuna. Aristóteles mantiene que es imprescindible dar cuenta también de la presencia de lo azaroso. La aportación de la Poética es muy relevante al respecto.

Palabras clave: Ética, azar, casualidad, ser coincidental, yerro moral, virtud, felicidad, Aristóteles.

*Recibido: 13-01-06. Aceptado: 20-03-06. 
Mary Clothier es uno de los caracteres centrales de la novela titulada Friends and Lovers, de la escritora inglesa Iris Murdoch, Profesora de Filosofía que fue de la Universidad de Oxford. Encontramos a la sazón a Mary, cuyo marido murió atropellado por un automóvil frente a su casa de Londres, en una situación dramática. Su hijo Pierce, desesperado por el primer desengaño amoroso, ha entrado nadando en una gruta de la costa que ha sido ya casi totalmente invadida por la marea. Mary, en una barca guardacostas, espera el desenlace de su búsqueda. Éste es un fragmento de su "flujo de conciencia":

La muerte ocurre, el amor ocurre, y la vida humana está pletórica de azares y accidentes. Si una ama algo tan frágil y mortal, y una ama y sigue amando, al igual que el terrier persigue su presa, ¿no es inevitable que el amor que una siente sufra alteraciones? Tan sólo hay un imperativo absoluto, el imperativo de amar. Sin embargo, ¿cómo es posible tolerar el dolor de amar a lo que ha de morir, a lo que ya ha muerto? "¡Oh, muerte, acúname en el sueño, dame silencioso descanso! Deja que mi fatigada alma culpable abandone mi pecho cuitado...". No somos más que una porción de tierra, un conjunto de debilidades, una sombra que cruza el caos del mundo contingente. Como sea que la muerte y el azar constituyen la sustancia de cuanto existe, si el amor ha de dirigirse a algo, el amor habrá de ser amor a la muerte y al azar. Este amor alterado navega en un océano de contingencias, entre formas de muertos, es un amor tan impersonal y frío que difícilmente puede reconocerse como tal, es un amor carente de belleza del que sólo se conoce el nombre, $\tan$ poco es lo que se asemeja a las vivencias. Éste era el amor que Mary sentía ahora por su marido muerto, y por el fantasma sin rostro de su hijo quizá ya ahogado ${ }^{1}$.

\footnotetext{
${ }^{1}$ Iris Murdoch: Amigos y amantes, Trad. de Andrés Bosch. Barcelona: Lumen 2005, pp. 472-473.
} 
Nadie se extrañará al recordar que la autora de este texto era especialista en ética griega, porque en él se pueden adivinar ecos de coros de las tragedias de la Grecia clásica, en las que cuestiones como las del azar, la contingencia y la muerte aparecen indisolublemente vinculadas a la condición humana. Y no es osado aventurar que la moral de los pensadores de la Escuela de Atenas, y muy especialmente la ética de Aristóteles, es un intento de tematizar e intentar resolver conceptualmente los desgarradores problemas humanos que se habían presentado de forma narrativa en las dramatizaciones de lo azaroso y contingente por parte de Esquilo, Sófocles y Eurípides.

Lo que una ética como la de Aristóteles puede añadir al enfoque poético propio de la tragedia es su tratamiento metódico. Ahora bien, el Estagirita insiste una y otra vez en que la filosofía práctica no posee un carácter científico, porque no está encaminada al conocimiento de lo universal, sino que apunta a la realización de unas acciones que siempre han de ser singulares y estar contextualizadas ${ }^{2}$. Los propios bienes, que - como fines de la acción humana- estudia la ética, caen bajo la sombra de la incertidumbre, "por haber sobrevenido (symbainein) males a muchos a consecuencia de ellos; pues algunos han perecido a causa de su riqueza, y otros por su valor" ${ }^{3}$, según apunta Aristóteles en el libro I de la Ética a Nicómaco.

Parece que no es posible, tampoco aquí, superar los límites cognoscitivos de la narrativa trágica, porque en la indagación moral tropezamos desde el comienzo con los mismos enigmas que conferían a la tragedia tanto su tremenda fuerza emotiva como su notoria debilidad racional. El buen carácter de Edipo se vuelve contra él —en la tragedia de Sófoclescuando pretende salvar de nuevo a Tebas del infortunio, al regresar del pasado el fantasma de un parricidio que él ignoraba haber cometido. Mientras que el Agamenón de Esquilo paga con la obligación de sacrificar a su hija Ifigenia la buena disposición de acudir al dios para sacar a su ejército de un callejón sin salida.

\footnotetext{
${ }^{2}$ Cfr. Ética a Nicómaco I, 3, 1095 a 6.

${ }^{3}$ Ética a Nicómaco, I, 3, 1094 b 18-19. Traducción de Julián Marías y María Araujo.
} 
¿Qué podrá hacer una filosofía que se propone buscar las primeras causas de lo real cuando se enfrenta con fenómenos en los que la relación etiológica parece estar ausente? En el caso de Aristóteles, su gran baza metódica es la flexibilidad que le proporciona el discurso analógico, en el que se establece, de un lado, una decisiva diferenciación entre la razón teórica y la razón práctica y, de otro, una distinción fundamental entre los diversos sentidos del ser.

Vamos a fijarnos primeramente en este último aspecto, porque constituye la articulación teórica más importante de la metafísica aristotélica, de la que - casi siempre implícitamente- se sirve la ética para plegarse al panorama abigarrado y variable de la vida humana, en la que se registran esa suerte de accidentes morales, cuando acontece que la fortuna y el infortunio parecen trastocar los proyectos existenciales más nobles y sensatos.

To on légetai pollachôs. El recurso a la pluralidad significativa del ser no es un virtuosismo gramatical, sino el reconocimiento de la riqueza y variedad de los fenómenos que Aristóteles trata de "salvar" en su filosofía. La índole no completamente aferrable de la realidad se traduce en una complejidad conceptual y semántica ante la que la correspondiente tripleta neopositivista —existencia, predicación e identidad- no pasa de ser un simplismo. Si este aspecto no plenamente formalizable del mundo se manifiesta en las cuatro rúbricas de la clasificación aristotélica de los sentidos del ente, se hace especialmente patente en la discriminación entre el ser en sí y el ser coincidental, ens per se y ens per accidens (on kath'hautó y on katá symbebekós) ${ }^{4}$.

Uno de los ejemplos de ens per accidens o coincidental que pone Aristóteles se hizo famoso a lo largo de la escolástica medieval y postmedieval por haber quedado reflejado en multitud de dibujos o grabados que ilustraban los pertinentes pasajes del corpus aristotélico: Alguien, al cavar un hoyo para plantar un árbol, encuentra un tesoro; en efecto, descubrir un tesoro es un accidente para el que planta un árbol, pues no se sigue necesariamente lo uno de lo otro ni después de lo otro, ni sucede

${ }^{4}$ Alejandro LLAnO: Metaphysics and Language, New York; Hildesheim: G. Olms 2005 , p. 147.

Tópicos 30 (2006) 
generalmente que el que planta encuentre un tesoro ${ }^{5}$. Algo se da en una cosa, pero no precisamente por ser esta $\cos ^{6}{ }^{6}$ o por encontrarse en la circunstancia en la que realmente se encuentra, sino por una pura coincidencia que no guarda relación con el fin de la acción o con el presente estado de cosas. Así que el accidente se ha producido o existe, mas no en cuanto tal, sino en cuanto otro ${ }^{7}$. El ser coincidental queda al margen de la finalidad que establece para cada ente su propia naturaleza y para cada acción el propósito que la guía. Lo que es por accidente no es según un haber o un actuar propio, que le corresponda de suyo, sino según un haber o un actuar que en realidad pertenece a otro y que, por un mero acontecer, por una pura coincidencia, se puede decir de él. Según MillánPuelles, este ser eventual puede describirse como "lo que un ente es o lo que es un ente por algo extrínseco a su esencia”. De manera que de lo que solamente existe por accidente no se puede decir propiamente que es, sino que sucede o acontece (accidit).

Para acercarnos a la realidad de los accidentes morales y considerar su posible relevancia ética, fijémonos por un momento en un tipo de ser coincidental que presenta especial significación antropológica. Se trata de la suerte o fortuna. La fortuna (týche) se distingue del simple azar (autómaton) en que se refiere a objetos que proceden de la acción humana, o bien influyen en ella y en la prosperidad de la persona que la lleva a cabo ${ }^{8}$. A pesar de su incidencia en la condición humana, la fortuna es algo que escapa de nuestro raciocinio (paralogon), ya que el raciocinio se ocupa o bien de las cosas que son siempre o de las que son por lo general, mientras que la fortuna presenta un carácter indeterminado. Como todo el mundo sabe, la fortuna es incierta, ya que ninguna de las cosas que suceden fortuitamente puede darse por segura. En definitiva, la fortuna es una causa coincidental o per accidens en el campo de las acciones libres o, al menos, voluntarias?

\footnotetext{
${ }^{5}$ Metafísica V, 30, 1025 a 15-21. Traducción de V. García Yebra.

${ }^{6}$ Metafísica V, 30, 1025 a 23.

${ }^{7}$ Metafísica V, 30, 1025 a 28-29.

${ }^{8}$ Cfr. Física II, 6, 197 a 36-b 6.

${ }^{9}$ Física II, 5, 197 b 18-22.
} 
Lo más inquietante de la cuestión, sin embargo, estriba en que, no por carecer en sí misma de explicación racional, la fortuna deja de tener importancia ética. La tragedia griega nos ilustra acerca de cómo la suerte pone no pocas veces a los protagonistas del drama ante conflictos morales de los que parece imposible escapar sin haber cometido una grave falta. Baste con recordar los casos de Antígona y Creonte en la Antígona de Sófocles. El ser humano es vulnerable, pero no sólo en su dimensión corporal o en sus empeños sociales, sino en el núcleo personal más íntimo y profundo. Para alcanzar una vida lograda, no les basta a la mujer y al hombre con forjarse un buen carácter a golpe de adquisición y ejercicio de las virtudes. Como insiste Martha Nussbaum en su libro The Fragility of Goodness ${ }^{10}$, no es suficiente ser bueno, sino que hay que vivir bien y actuar bien, lo cual resulta frecuentemente comprometido por eventos ajenos que nos afectan o por actuaciones desafortunadas de uno mismo, llevadas a cabo con la mejor intención del mundo.

Claro aparece que en principio no se puede cargar en la cuenta moral de nadie, ni para bien ni para mal, algo que se ha producido de manera puramente accidental. El hombre no es responsable de todo lo que hace, sino tan sólo de lo que hace voluntariamente ${ }^{11}$. Como ha indicado Amalia Quevedo, con referencia a Aristóteles:

tanto las acciones forzosas como las fortuitas quedan fuera de su responsabilidad, aunque por diversos motivos; éstas, porque carecen de causa propia y de razón que las justifique, aquéllas porque tienen como causa a un agente exterior a quien deben imputarse. El hombre verdaderamente responsable debe saber prescindir de los efectos fortuitos (no previsibles) que se sigan de su acción, consciente de que no es él la causa culpable de ellos. Ha de saber que no puede responder por ellos, no por una deficiencia personal, sino por la misma índole de los efectos fortuitos, indeterminados y carentes de causa propia. Nadie puede determinarse

\footnotetext{
${ }^{10}$ Martha C. NussBaum: The Fragility of Goodness. Luck and Ethics in Greek Tragedy and Philosophy, Cambridge: University Press 1986.

${ }^{11}$ Cfr. Alejandro Llano: El futuro de la libertad, Pamplona: Eunsa 1985, p. 206.
} 
con respecto a lo que es de suyo indeterminado, ni dar razón de lo que intrínsecamente carece de ella; en síntesis, nadie puede hacerse cargo de lo que se sigue por puro accidente de sus propias acciones ${ }^{12}$.

La humana responsabilidad siempre es limitada. Una responsabilidad total terminaría por abocar a una total irresponsabilidad, según suele acontecer con los que se preocupan de problemas globales en los que no pueden incidir, sintiéndose con ello descargados de atender a los cometidos cercanos que realmente les competen. Si fuéramos responsables de todo, no seríamos responsables de nada.

La imputabilidad de una acción presupone conocimiento. Pero la ignorancia también puede ser, al menos parcialmente, culpable. El ser coincidental — que según Aristóteles se asemeja al no-ser ${ }^{13}$ — comparece frecuentemente en nuestro horizonte ético por la vía de la carencia o la privación. Así comienzan a apuntar las perplejidades motivadas por los accidentes morales. La pregunta "¿pero te das cuenta de lo que estás haciendo?" no carece de sentido. Pues alguien, señala Aristóteles:

podría ignorar lo que hace, $\mathrm{y}$ así quien dice que una cosa se le escapó en la conversación, o que no sabía que era un secreto, como Esquilo los misterios, o que al querer mostrarlo se disparó, como el de la catapulta. También podría creerse que el propio hijo es un enemigo [...]; o que tenía un botón la lanza que no lo llevaba, o que una piedra corriente era piedra pómez; o dar una bebida a alguien para salvarlo y matarlo, o herir a otro cuando quería tocarlo, como los que luchan a la distancia del brazo. [...] Aquél de quien se dice que ha hecho algo involuntariamente en virtud de esta clase de ignorancia, tiene que sentir pesar y arrepentimiento por su acción ${ }^{14}$.

\footnotetext{
${ }^{12}$ Amalia Quevedo: "Ens per accidens". Contingencia y determinación en Aristóteles , Pamplona: Eunsa 1989, p. 424.

${ }^{13}$ Cfr. Metafísica VI, 21026 b 21.

${ }^{14}$ Ética a Nicómaco III, 1, 1111 a 8-21.
} 
Recordemos la importancia que en la ética kantiana presenta el axioma "tú puedes, porque tú debes"; axioma que, a su modo, se encuentra también en Aristóteles cuando deduce del hecho social de la alabanza y del reproche la existencia de la responsabilidad propia de la persona ${ }^{15}$. El claroscuro de inocencia y culpabilidad comparece, sobre todo, en el caso de la hamartía, el yerro, el error práctico, ajeno a las causas de la maldad del carácter, pero que, a pesar de todo, puede marcar el valor moral de una vida. Aristóteles nos dice que la tragedia trata de personas buenas que caen en la desgracia, "no por defectos del carácter ni por perversidad, sino por una especie de hamartía"16. Cuando la culpa se origina en el agente, se tiene el tipo de yerro trágico que constituye la hamartía; mientras que, si surge fuera de él, es víctima de un infortunio (atýche$\mathrm{ma})^{17}$. Así pues, caer en la desgracia por hamartía es precipitarse en ella por causa de una especie de equivocación práctica causalmente inteligible y no simplemente fortuita, que se atribuye en cierto modo al agente y que, sin embargo, no es la expresión de un mal hábito de su temple moral. La hamartía engloba fallos éticos más o menos censurables: la ignorancia no culpable de Edipo, el sacrificio de la hija de Agamenón — deliberada pero impuesta en gran parte por las circunstancias-, las desviaciones pasionales del acrásico en contra de su buen carácter, motivadas por la pasión erótica o por una cólera indominable. Es como si se produjera un distanciamiento o desviación temporal de la actitud moral básica. Son, por tanto, faltas importantes que no proceden de la perversidad del temple personal, pero que pueden condicionar negativamente el resto de la existencia. Como la acción no ha sido resultado del propio ethos $^{18}$, se halla siempre presente un factor de infortunio o mala suer-

\footnotetext{
${ }^{15}$ Cf. Fernando InCIARTE: El reto del positivismo lógico, Madrid: Rialp 1974, p. 179.

${ }^{16}$ Poetica 1453 a 9-10. Cfr. Richard SorabJi: Necessity, Cause and Blame. Perspectives on Aristotle's Theory, London: Duckworth 1980, pp. 295-298.

${ }^{17}$ Ética a Nicómaco V, 8, 1135 b 19-20.

18 “'Ethos' hat dann bei Aristoteles zugleich auch immer die Bedeutung von 'Haltung' und 'Charakter des einzelnen' ”. Joachim RITTER: "Zur Grundlegung der praktischen Philosophie bei Aristoteles", en Manfred RIDEL: Rehabilitierung der praktischen Philosophie, II, Freiburg: Rombach 1974, pp. 486-487.
} 
te, constituido por una coincidencia, circunstancial a veces, o motivada otras por la inoportunidad de las pasiones desatadas ${ }^{19}$.

Incluso el hombre bueno puede realizar acciones que pesen sobre sus recuerdos y lastren en alguna medida su recorrido. Todos tenemos el riesgo de provocar algún accidente que perjudique a las personas más queridas, y es bueno que - si nos sobreviene esta desgracia - lo lamentemos como merece. El estólido, que no se conmueve ni entristece por haber cometido algo doloroso - o incluso terrible - se encontraría en una tesitura semejante a la de Agamenón, que pareció no sufrir por tener que sacrificar a su hija Ifigenia, y mereció el reproche de insensibilidad moral. Es un logro de la ética aristotélica el haber otorgado a las emociones y sentimientos un importante papel en la vida lograda, concediéndoles relevancia en la asignación del bien y del $\mathrm{mal}^{20}$.

Los sentimientos no sólo tienen importancia a parte post, una vez realizada la acción correspondiente, sino que cumplen también una función anticipadora en la comprensión moral de situaciones complejas, ya que se dirigen intencionalmente a fenómenos particulares y diferenciados, con una penetración e inmediatez que la pura razón no puede alcanzar. Siglos más tarde, Tomás de Aquino elaboró en esta línea su noción de conocimiento por connaturalidad, que encontraría un posterior desarrollo en la teoría fenomenológica de la Einfühlung o empatía, tan penetrantemente estudiada por Edith Stein.

En concreto, las emociones y pasiones constituyen la instancia volitiva que más característicamente responde a la indeterminación y accidentalidad que acaecen en el mundo sublunar, y sobre todo en el ámbito interpersonal y político. A ellas está encomendada en un primer momento la reacción frente a lo coincidental, de manera que ab initio el agente se pliega a lo real que escapa a su voluntad. Actúan como una especie de sismógrafo que detectara situaciones antropológicas y éticas antes de que resulten registradas por la inteligencia. Hay que advertir, con todo, que

\footnotetext{
${ }^{19}$ He seguido en este punto a NussBaum: The Fragility of Goodness..., pp. 474475.

${ }^{20}$ Cfr. Martha Nussbaum: Aristotle's De Motu Animalium, Princeton: University Press 1978, p. 218.
} 
una exageración del significado antropológico del sentimiento conduce prontamente a una pérdida del sentido de lo esencial y lo necesario, con la consiguiente exageración de la importancia de lo accidental ${ }^{21}$.

La segunda y decisiva instancia de respuesta a la presencia de lo coincidental en el ámbito práctico corresponde, sin duda, a la phrónesis. La prudencia tiene como objeto lo particular, con lo que uno llega a familiarizarse por experiencia. Es evidente, entonces, que la prudencia no es ciencia, porque se refiere a lo práctico, que es lo más particular ${ }^{22}$. Resulta propio, entre otras cosas, de la prudencia el intento de prever las consecuencias de la acción, las cuales —al no pertenecer a la acción mismapresentan una inevitable dimensión accidental. De ahí que la completa anticipación del horizonte de una actuación no sea posible, ni siquiera deseable, porque supondría el ejercicio de un dominio sobre el curso de los acontecimientos que vendría a ser desmesurado para la condición humana. La presencia del albur, de lo inesperado y sorprendente, forma parte de la frescura e interés de nuestro andar por el mundo. La incertidumbre que esta situación conlleva es, sin duda, un bello riesgo que Aristóteles supo mantener vivo en sus indagaciones éticas.

Constituye un mérito de algunas interpretaciones contemporáneas de la ética de Aristóteles, y una de las mejores aportaciones de la rehabilitación de la filosofía práctica, el haber vuelto a actualizar el valor cognoscitivo propio de las virtudes morales. Nada hay más contrario a la visión que el Estagirita tiene de los hábitos operativos que el concebirlos como meras habilidades o destrezas, por utilizar la terminología con la que la pedagógica oficial nos fatiga en las tareas educativas. Porque las excelencias morales no son automatismos, sino potenciaciones de un conocimiento práctico que se alcanza justo al hilo de la praxis huma$\mathrm{na}^{23}$. Como dice Aristóteles en frase genial, "para saber lo que tenemos que hacer, hemos de hacer lo que queremos saber" 24 . Y es que "no ad-

${ }^{21}$ Quevedo: “Ens per accidens”..., pp. 425-426.

${ }^{22}$ Ética a Nicómaco VI, 8, 1142 a 14-16 y 24-26.

${ }^{23}$ Günther BIEN: "Die menschlichen Meinungen und das Gute. Die Lösung de Normproblems in der Aristotelischen Ethik", en Manfred RIEDEL: Rehabilitierung del praktischen Philosophie, I, Freiburg: Rombach 1972, p. 370.

${ }^{24}$ Ética a Nicómaco, II, 1, 1103 a 32-33. 
quirimos los sentidos por ver muchas veces u oir muchas veces, sino a la inversa: los usamos porque los tenemos, no los tenemos por haberlos usado. En cambio, adquirimos las virtudes mediante el ejercicio previo" 25 . Este planteamiento implica, a todas luces, una circularidad. Pero no se trata de una circularidad viciosa, sino de una circularidad hermenéutica, según acontece siempre en las articulaciones capitales de la ética aristotélica. Queda claro, en todo caso, que no hay valores morales innatos. Ni los jóvenes son sinceros por ser jóvenes, ni los viejos son sabios por ser viejos.

¿Por dónde empezar? Es un viejo problema que, en cuanto concierne al conocimiento está magníficamente planteado en el Menón platónico. Por lo que se refiere a la adquisición de la virtud, preciso es tener en cuenta que para Aristóteles la ética es "una cierta disciplina política" $^{26}$. La excelencia no la puede conseguir nadie individualmente, ya que posee una índole comunitaria. Tal es, en rigor, el punto de partida: el encontrarnos viviendo ya en una comunidad que practica unas virtudes, aprecia unos bienes y respeta unas reglas del juego. En realidad, siempre nos encontramos en una comunidad de tal tipo. El individuo desarraigado y solitario es una ficción contemporánea, la cual parece irse haciendo trágicamente real a la vista del aislamiento y la ausencia de solidaridad que se extienden en una sociedad como la nuestra, donde todo parece oscilar entre el azar y la necesidad mostrenca que, al cabo, acaban por identificarse. En cualquier caso, la ética como esfuerzo asocial conduce necesariamente al fracaso. Según Aristóteles, la educación y la legislación ${ }^{27}$ son imprescindibles para alimentar inicialmente esa especie de circuito electrónico redundante que, como la propia vida, viene a ser la moral. Cuando todavía no somos buenos, hemos de comportarnos como si lo fuéramos por obra de una paideia hecha de enseñanzas, buenos ejemplos y alguno que otro reproche o corrección.

La moral aristotélica no se agota en una ética de normas. Entre otras cosas, porque las reglas deben ser aplicadas a los casos concretos, donde

\footnotetext{
${ }^{25}$ Ética a Nicómaco, II, 1, 1103 a 28-31.

${ }^{26}$ Ética a Nicómaco, I, 2, 1094 b 11.

${ }^{27}$ Cfr. Ética a Nicómaco, IX, 9, 1179 b 31-35.
} 
lo de suyo y lo coincidental se hallan entreverados de modo casi indiscernible. Y resulta que - como vio lúcidamente Wittgenstein- no hay reglas para la aplicación de las reglas. De lo contrario, iríamos a un proceso al infinito. Se requiere otra instancia que nos proporcione un conocimiento cuasi-intuitivo de la situación moral concreta. Instancia que no es otra que la phrónesis o prudencia.

En el ámbito moral no es suficiente con la habilidad en el manejo de medios, que puede resolverse racionalmente y sin compromiso personal. Aquí el problema es también acertar el fin y esto ya no depende de instancias racionales sino de la corrección de las tendencias, pues son éstas las que identifican los fines. El problema ético no consiste sólo en acertar o no en el blanco propuesto [...], sino también en acertar o no el blanco. No verlo así conduce a la tecnificación de la ética. Según un modelo técnico, la consecución del bien humano requiere sólo un tipo de capacidad: inteligencia $^{28}$.

Según el modelo ético, en cambio, han de entrelazarse dinámicamente el querer y el saber. Se trata de conocer el bien. Pero el bien humano sólo se conoce por la experiencia del actuar, en la que las particularidades y los accidentes comparecen de continuo. Nuestras decisiones nunca están completamente respaldadas por el saber. De ahí que la experiencia moral sea, constitutivamente, experimento. Kant viene a expresar lo mismo con otras palabras: en la praxis humana la necesidad de decidirse excede las posibilidades del conocer. En la praxis moral tenemos que disponer de lo que aún no poseemos, decidirnos por lo que no está, sin nosotros, del todo decidido. "Desasistida de la práctica, de querer la realización del bien, la razón se encuentra a ciegas. Querer el bien es el camino que conduce a saber algo sobre el bien, aunque saber que hay que querer el bien es, por supuesto, la primera condición para buscarlo. Esta colaboración entre un saber que uno no sabe y un querer saber lo que no se sabe es

\footnotetext{
${ }^{28}$ Miquel BASTONS I PRAT: La inteligencia práctica. La filosofía de la acción en Aristóteles, Barcelona: Prohom 2003, pp. 66-67.
} 
lo que Aristóteles llama "proaíresis""29, es decir, elección o decisión. Por eso Aristóteles puede decir que "la elección es o inteligencia deseosa o deseo inteligente, y esta clase de principio es el hombre" ${ }^{30}$. La elección o decisión consiste en un decidir sobre algo que siempre es, simultánea e inseparablemente, un decidirse. Necesaria reflexividad que implica, por parte del agente, un compromiso y un empeño. En este sentido, la obligación moral es en cada caso mi obligación o tu obligación. Siempre es concreta y no puede obviar el hecho de que la situación en la que se produce no sólo está configurada por la esencia de cada cosa, sino también por "lo otro que la esencia", es decir, por el ser coincidental.

La decisión incluye los dos componentes: tendencia recta y conocimiento verdadero. Aristóteles lo señala cuando indica que la elección no puede ser recta sin virtud ni sin prudencia, puesto que una determina el fin y la otra hace realizar las acciones que conducen al fin ${ }^{31}$. Esta relación circular y recíproca entre la calidad moral y la prudencia es similar a la que existe entre inteligencia y deseo. Del mismo modo como en la decisión la inteligencia se hace deseosa y el deseo inteligente, en un diálogo recíproco, así — dirá Aristóteles_ " "no es posible ser bueno en sentido estricto sin prudencia, ni prudente sin la virtud moral" 32 .

$\mathrm{Al}$ hilo de nuestros empeños morales se va configurando una suerte de instinto ético que nos habitúa a actuar de manera que sea posible dar con el significado ético de una tesitura moral concreta y completa. Más que de estar cierto, se trata de acertar, a base de rectificar una y otra vez, hasta el punto de que cabe decir que, en el ámbito de los compromisos prácticos, la recta ratio es una correcta ratio ${ }^{33}$. (En cambio, a la ciencia no le corresponde propiamente la rectitud, como tampoco el yerro, en el sentido de hamartía ${ }^{34}$ ). Naturalmente, este continuo ajuste no consiste en una mera adaptación al curso común de los acontecimientos,

\footnotetext{
${ }^{29}$ InCIARTE: El reto del positivismo..., pp. 206-207. Cfr. pp. 208-211.

${ }^{30}$ Ética a Nicómaco, VI, 2, 1139 b 4-6.

${ }^{31}$ Ética a Nicómaco, VI, 13, 1145 a 4-6.

${ }^{32}$ Ética a Nicómaco, VI, 13, 1144 b 30-32. Cfr. BASTONS: La inteligencia práctica..., p. 66.

${ }^{33}$ INCIARTE: El reto del positivismo..., p. 183.

${ }^{34}$ Ética a Nicómaco, VI, 9, 1142 b 9-10.
} 
buscando siempre el propio provecho con más astucia que prudencia. Los que proceden así buscan los bienes naturales simplemente porque les conviene. Son buenos sólo accidentalmente, de manera oportunista. En cambio, la persona éticamente madura persigue el bien donde quiera que se halle, sencillamente porque es un bien. Tal es la conducta noble que Aristóteles, en la Ética a Eudemo, no duda en calificar de bella. Y sucede que, a estos hombres nobles, incluso las cosas útiles y convenientes les resultan bellas, porque las persiguen en lo que tienen de bueno y no sólo en su aspecto subjetivamente provechoso ${ }^{35}$. La persona noble es, diríamos hoy, la que tiene "buen gusto": aquélla a la que lo bueno le parece bueno y le complace.

La verdad práctica tiene que ver con aquello que se comporta siempre de diversa manera, con lo endechómenon kai allôs echein. De ahí que no sólo esté permanentemente acechada por la posibilidad de error, sino que está necesariamente mediada por el error. El genuino campo del error es el la posibilidad de ser y no ser. Pues bien, así como lo propio de la teoría — señala Inciarte - es ir cancelando posibilidades, a medida que se pasa de lo accidental a lo esencial, y de la forma al acto, hasta alcanzar el acto puro de lo que no se puede comportar de otra manera por ser, sustantivamente, su propio comportamiento; así como eso es lo propio de la especulación, lo característico de la práctica, en cambio, viene dado por el hecho de que la realidad crea su propia posibilidad, la cual — por paradójico que suene- sigue a aquélla en lugar de precederla. Y a esta paradójica anticipación le es inherente una cierta no-verdad, a partir de la cual surgen las decisiones acertadas, que suponen el logro de una verdad práctica comprometida con la acción y superadora — aunque nunca plenamente - de la perplejidad moral ${ }^{36}$.

Por todo lo que venimos diciendo hasta ahora, ya sabemos que la inevitable presencia del error en el discurrir ético no procede únicamente de la limitación de nuestras facultades cognoscitivas y desiderativas. Surge de la propia realidad, de un mundo en el que las cosas no son plenamente lo que son. No poseen completamente su propio ser, ni tam-

\footnotetext{
${ }^{35}$ Ética a Eudemo, VIII, 1249 a 1-18.

${ }^{36}$ Cfr. INCIARTE: El reto del positivismo..., pp. 185-186.
} 
poco tienen de manera parcial un ser que Dios poseyera completamente, porque —utilizando la expresión de Tomás de Aquino- el Ipsum esse subsistens no se debe entender como si tuviera plenamente el ser, sino como poseyendo enteramente su propio ser. Los mismos entes finitos son fragmentarios, aspectuales, de modo que si respecto a ellos nos comportáramos con una certidumbre incuestionable, estaríamos incurriendo en una básica falsedad, en un error de planteamiento, en una especie de hamartía total acerca de cuyas consecuencias la historia ideológica y política del siglo XX podría proporcionarnos algunas enseñanzas.

A pesar de que el ser coincidental tiene un carácter metafísicamente secundario o derivado, su reconocimiento - sobre todo en el terreno ético- presenta la mayor importancia, ya que nos revela que el mundo de nuestra experiencia, nuestro campo de acción, no es un tejido homogéneo y sin fisuras, una realidad unívoca, sino un mundo plural y diferenciado, abierto a ulteriores modificaciones, nunca completamente determinado. En el universo que habitamos, el orden no elimina completamente el desorden: el orden es el límite del desorden. Lo cual se aprecia con especial claridad en el ámbito práctico, donde la justicia no suele pasar de ser el límite de la injusticia. Es más, si se pretende implantar una justicia total, sin tener en cuenta la accidentalidad que nos rodea y que nosotros mismos generamos, se produce la mayor de las injusticias ${ }^{37}$.

Nuestro mundo físico y social no es un perfecto ensamblaje de esencias puras, penetrable de punta a cabo por la razón. No se niega con esto - y Aristóteles menos que nadie- que haya realmente esencias: el modo de ser necesario de cada cosa, su haber propio y constitutivo. Pero existe también, como sabemos, lo que no es según la esencia, sino según lo otro que la esencia. De ahí que declinemos el ente en diversos sentidos para plegarnos a la realidad, que no es un bloque monolítico ni absolutamente fijo. No se trata sólo ni principalmente de que las formas esenciales de la mayor parte de las cosas nos sean desconocidas - como repite Tomás de Aquino una y otra vez-, es que las realidades humana y mundanales no están completamente determinadas por las formas esen-

${ }^{37}$ Cfr. Alejandro Llano: Metaphysics and Language. . , pp. 154-155; 308-310; 322 323. 
ciales de las cosas o de las personas: no son sólo lo que esencialmente son y, por eso mismo, no son plenamente lo que son. Hay lo otro que el ente esencialmente determinado: hay, realmente, indeterminación. Admitir que hay realmente indeterminación y determinación nos abre hoy a una insólita visión del mundo, cuyas consecuencias habrá que explorar, tanto en el ámbito teórico como especialmente en el práctico.

Aristóteles no acepta, para el mundo de lo generable y corruptible, el principio de plenitud - propuesto en su tiempo por lo megáricos y en el siglo XX por Lovejoy, Hintikka y Knuutila— según el cual ninguna genuina posibilidad puede permanecer siempre sin realizarse, porque lo que nunca se realiza no es posible ${ }^{38}$. Y es que el Estagirita mantiene como una de sus tesis capitales, en metafísica y en ética, precisamente lo contrario: la no-plenitud de las cosas de nuestro entorno natural y político, cruzadas por la contingencia y la coincidencia, abiertas siempre a ulteriores determinaciones, que se actualizarán o no se actualizarán. Este principio de no-plenitud podría enunciarse así: las cosas físicas y los empeños morales no son ni serán todo lo que pueden ser, porque no son plenamente lo que son. Ninguno de esos entes finitos se identifica plenamente con su esencia, ni por lo tanto es cumplidamente lo que ello mismo es, porque su carácter potencial hace que exista temporalmente y sea sujeto de determinaciones accidentales que le sobrevienen.

La posibilidad real, a diferencia de la posibilidad lógica, presenta un carácter dialéctico: lo que puede ser, puede no ser. La admisión de esta "posibilidad dialéctica" configura un mundo humano poroso, dinámico, en continua reorientación teleológica hacia una plenitud siempre perseguida y nunca plenamente alcanzada; un mundo en el que - como dice el Profesor Leonardo Polo- todo está “alejado" y "retrasado", ya que la potencia es inseparablemente principio de movimiento y de resistencia inercial al movimiento. No se extiende ante nosotros un horizonte sin fracturas, perfectamente articulado, sino un panorama minado por la

\footnotetext{
${ }^{38}$ Arthur Lovejoy: The Great Chain of Being. A Study of the History of an Idea, New York: Harper \& Row 1967, p. 52. Cfr. Jaako HinTIKKA: Time and Necessity. Studies in Aristotle's Theory of Modality, reimp., Oxford: Clarendon 1975; Simo KNUUTILA (ed.): Reforging the Great Chain of Being. Studies of the History of Modal Theories, Dordrecht: Reidel 1981.
} 
accidentalidad, plagado de coincidencias que no fluyen de ninguna necesidad interna, ya que no tienen causa propia o, mejor, propiamente no tienen causa. Estamos ciertamente en una ciudad y en un cosmos, pero ni el orden social ni el físico son cabales, pues no excluyen — sino que implican - la discontinuidad, la oposición, el azar y el infortunio. "El mejor de los mundos posibles" ni existe ni puede existir ${ }^{39}$.

En tales condiciones, ¿le es posible al ser humano alcanzar la felicidad? Para intentar responder a este interrogante decisivo, es preciso notar que Aristóteles entiende por eudaimonía — la palabra que nosotros traducimos por "felicidad" — "una actividad del alma según la virtud perfecta" 40 . Conviene tener en cuenta esta índole activa de la felicidad, porque el primer malentendido que puede surgir estriba en entender esta plenitud humana como una suerte de estado que a uno le ha tocado en suerte por obra del destino o de alguna divinidad. Es una cuestión largamente discutida en la Ética a Eudemo ${ }^{41}$, porque parece una experiencia común en todas las culturas que no siempre es al hombre bueno, a la mujer íntegra, a quienes les va mejor en la vida.

Algunas personas parece que han nacido para ser felices, para lograr su vida. Todo les sale bien. Según sugiere el propio vocablo eudaimonía, es como si estuvieran poseídos por un genio benévolo, bendecidos por un ángel favorable. De otros, en cambio, se podría afirmar justamente lo contrario. "Hay algunos que nacen con estrella y otros que nacen estrellados", dice la sabiduría popular. ¿Qué hacen estos últimos para que su vida vaya de tropiezo en tropiezo hasta el desconcierto final? Tienen mala suerte. En el girar de la rueda de la fortuna siempre acaban quedando en la parte de abajo.

Pero hay algo muy hondo que nos repugna en este enfoque de biografías marcadas, aunque los oráculos y los augurios, los vates y adivinos, encuentren tanto eco en el siglo XXI como en el V antes de Cristo. Una cosa tan seria como el logro de la vida — pensamos con razón- no

\footnotetext{
${ }^{39}$ Cfr. Tomás De Aquino: Summa Theologiae, q. 25, a. 6. Vid. Alejandro Llano: "Aquinas and the Principle of Plenitude" en David GALLAGHER (ed.): Thomas Aquinas and his Legacy, Washington D. C.: The Catholic University of America Press 1993.

${ }^{40}$ Ética a Nicómaco, I, 13, 1102 a 5-6.

${ }^{41}$ Cfr. Ética a Eudemo, VIII, 2, 1246 b 37 ss.
} 
puede depender del azar, de la situación de los astros al nacer o de algo llamado "destino", tan solemne como inexistente. El éxito de la propia vida no es algo innato, no se hereda ni se lleva escrito en la frente: está abierto a todos los individuos de la especie humana.

Supondría, empero, una falta de realismo no reconocer que nadie se encuentra al reparo de la aflicción, ni siquiera los presuntos bienaventurados de siempre. Y, al mismo tiempo, la ventura no está reservada a unos pocos selectos. Todos nos encontramos ante la alternativa de la alegría y la desgracia.

La felicidad es el fin final, el bien supremo" ${ }^{42}$; es "lo mejor, lo más hermoso y lo más agradable (áriston, kálliston, hédiston)" "43. Todo lo demás, los bienes exteriores, la amistad, el reconocimiento, se desea con vistas a la dicha. Pero, a su vez, la bienaventuranza necesita de estos bienes como medios o instrumentos. Son secundarios y accidentales a la felicidad, que no consiste en ellos, pero que no se vale sin ellos. Como afirma Aristóteles, la ventura:

necesita además de los bienes exteriores, pues es imposible o no es fácil hacer el bien cuando se está desprovisto de recursos. Muchas cosas, en efecto, se hacen como por medio de instrumentos, mediante los amigos y la riqueza y el poder político; y la falta de algunas cosas empaña la ventura, y así la nobleza del linaje, buenos hijos y belleza: no podría ser feliz del todo aquél cuyo aspecto fuera completamente repulsivo, o mal nacido, o solo y sin hijos, y quizá menos aún aquél cuyos hijos o amigos fueran absolutamente depravados, o, siendo buenos, hubiesen muerto. Por consiguiente, [...] la felicidad parece necesitar de esta clase de prosperidad, y por eso algunos identifican la buena suerte con la felicidad $^{44}$.

Sin unas condiciones de vida dignas, no es posible la práctica de la virtud y, por lo tanto, el logro de la felicidad. Pero no se debe identificar

${ }^{42}$ Ética a Eudemo, II, 1, 1217 a 22.

${ }^{43}$ Ética a Nicómaco, I, 8, 1099 a 25. Cfr. Ética a Eudemo, I, 1, 1214 a 8.

${ }^{44}$ Ética a Nicómaco, I, 8, 1099 a 30-b 8. 
la vida lograda con los medios que nos permiten aproximarnos a ella. Ahora bien, así como no se puede reducir la felicidad a la fortuna (eutychémata), tampoco cabe identificarla con la virtud ${ }^{45}$. Por esto — cito la Ética a Nicómaco_ - "los que afirman que el que está en la tortura, o el que ha caído en graves infortunios, es feliz si es bueno, voluntaria o involuntariamente dicen una vaciedad" 46 .

Mientras que la fortuna es variable, la felicidad es estable, porque la virtud modera la desgracia. De manera que en el hombre bueno

resplandece la nobleza, cuando soporta muchos y graves infortunios, no por insensibilidad, sino por ser noble y magnánimo. Porque si las actividades rigen la vida, como dijimos, ningún hombre virtuoso podrá llegar a ser desgraciado, ya que jamás hará lo que es vil y aborrecible. A nuestro juicio, en efecto, el que es verdaderamente bueno y prudente soporta dignamente todas las vicisitudes de la fortuna y obra de la mejor manera posible en sus circunstancias, del mismo modo que el buen general saca del ejército del que dispone el mejor partido posible para la guerra, y el buen zapatero hace con el cuero que se le da el mejor calzado posible $^{47}$.

La persona feliz posee un temple que no es inconstante ni variable. No resulta fácil apartarla de la ventura, ni siquiera cuando diversos infortunios vienen a coincidir en su vida. Pero el realismo de Aristóteles se encarga de precisar "a no ser que [los infortunios] sean grandes y muchos". Y entonces la cicatriz de la herida también es duradera, porque después de las desgracias "no volverá a ser feliz en poco tiempo, sino, si es que llega a serlo, al cabo de mucho y de haber alcanzado en ese tiempo grandes y hermosos bienes" 48 .

\footnotetext{
${ }^{45}$ Sigo a Amalia Quevedo en este punto. Cfr. Quevedo: “Ens per accidens”..., pp. 355-357.

${ }^{46}$ Ética a Nicómaco, VII, 13, 1153 b 19-21.

${ }^{47}$ Ética a Nicómaco, I, 10, 1100 b 30-1101 a 5.

${ }^{48}$ Ética a Nicómaco, I, 10, 1101 a 8-14.
} 
El alma vulnerada no se curará sino con la ayuda de mucho tiempo, de copiosas bendiciones y del consuelo de los amigos. Pero ¿qué hará en el caso límite de la amistad traicionada y, sobre todo, del amor no correspondido? Éste es un accidente moral para el que toda la sabiduría práctica no ofrece adecuada terapia. De tan extrema situación se alimenta la poética de todas las culturas avanzadas. Pero en ella casi sólo encontramos desesperanzas y lamentos.

El dolor es compañero inseparable de la vida humana. Esto lo recordó Nietzsche contra el sentimentalismo romántico. Como también se atrevió a cuestionar si es deseable la subordinación de los demás intereses al interés por la verdad. Por si esta sospecha no fuera suficiente, desde Marx y Freud se ha denunciado que el interés por la no-verdad puede incluir también solapadamente la supuesta voluntad de verdad. Ahora bien, quizá podamos recordar aquí a Hölderlin cuando nota que donde está el peligro surge también la salvación. Porque, ha señalado Inciarte $^{49}$, gracias a su relación constitutiva con el error, la verdad práctica, al contrario de la pura teoría, puede dar cuenta del interés por la no-verdad, que parece englobar el interés por la verdad, insertando así el interés por el error en el horizonte de la vida filosófica como vida orientada completamente hacia la verdad, según dijo en alguna ocasión Ernst Tugendhat. Por lo menos Aristóteles intenta mostrar, en su discurso ético, cómo se pueden aprovechar las apetencias e intereses humanos, que nos desorientan y nos dispersan, y que son por sí mismos opuestos a la vida desinteresada de la teoría, incluyéndolos en la perspectiva de la verdad práctica. En el marco de esta tarea de introducir los intereses en el ámbito filosófico, envolviendo la no verdad en la verdad práctica, Aristóteles desvela el hecho de que "toda la atención, tanto de la virtud como de la política, versa sobre el placer y el dolor, puesto que el que se sirve bien de ellos será bueno, y el que lo hace mal, malo"50. El largo camino de la moral conduce a través de la corrección constante de la

\footnotetext{
${ }^{49}$ INCIARTE: El reto del positivismo..., p. 184.

${ }^{50}$ Ética a Nicómaco, II, 3, 1105 a 10-14. "De ahí la necesidad de haber sido educado de cierto modo ya desde jóvenes, como dice Platón, para poder complacerse y dolerse como es debido; en esto consiste, en efecto, la buena educación". Ética a Nicómaco, 1104 b 11-13.
} 
apetencia y de la concupiscencia interesadas, mediante la recta ratio. Su propósito queda, al final de la ética, cumplido cuando se comprueba que la teoría es la actividad que más placer puede producir.

Se retoma así la tesis de que la felicidad consistirá en la actividad de acuerdo con el ergon propio, que es la contemplación intelectual. "Lo que es propio de cada uno por naturaleza - dice Aristóteles- es también lo más excelente y lo más agradable para cada uno; para el hombre lo será, por tanto, la vida conforme a la mente (kata ton noûn bíos), ya que eso es primariamente el hombre. Esta vida será también, por consiguiente, la más feliz" 51 . Es el audaz y problemático intento de hacer culminar el camino ético en una instancia trascendente a la propia ética. Parece ineludible procurarlo, porque el moralismo a ultranza conduce al inmoralismo, y — según vio lúcidamente Max Scheler- el afán autorreferencial por lograr una mayor perfección ética se halla internamente aquejado de fariseísmo ${ }^{52}$.

Pero el movimiento hacia una dimensión teológica, por la vía de la contemplación, presenta perfiles aporéticos en la moral del Estagirita. Aristóteles es bien consciente de que vivir de acuerdo con este elemento divino que hay en el hombre no se compadece bien con nuestra condición, sometida a la necesidad, al albur, a los conflictos morales, a las decisiones de otros que nos afectan poderosamente. También le parece, sin embargo, que sería empequeñecer la vida humana si consideráramos que el perfil de la ética se ha de encerrar en lo reductivamente antropológico.

\footnotetext{
${ }^{51}$ Ética a Nicómaco, X, 7, 1178 a 5-8.

52 “'Tiene razón en un punto Kant. Es imposible, por ley esencial, que las materias de valor 'bueno' y 'malo' se conviertan a su vez en materias del acto realizador ('voluntad'). Por ejemplo, el que no quiere hacer bien a su prójimo — de manera que le interese la realización de ese bien-y toma sólo la ocasión 'para ser bueno' o 'hacer el bien' en ese acto, no es bueno ni hace verdaderamente el bien, sino que en realidad es una especie de fariseo que quiere solamente aparecer ‘bueno' ante sí mismo”. Max SCHELER: Ética. Nuevo ensayo de fundamentación de un personalismo ético, $3^{\mathrm{a}}$ ed., revisada, Madrid: Caparrós 2001, pp. 74-75; cfr. El resentimiento en la moral, $2^{\mathrm{a}}$ ed., Madrid: Caparrós 1998 , pp. 61 y ss.
} 
No hemos de tener, como algunos nos aconsejan, pensamientos humanos puesto que somos hombres, ni mortales puesto que somos mortales, sino en la medida de lo posible inmortalizarnos (athanatítsein) y hacer todo lo que está a nuestro alcance por vivir de acuerdo con lo más excelente que hay en nosotros ${ }^{53}$.

No es que, como mantiene Martha Nussbaum ${ }^{54}$, los capítulos 6 a 8 del libro X de la Ética a Nicómaco supongan una recaída en el peor de los platonismos - el de los diálogos de la época intermedia, radicalmente corregidos, según esta autora, a partir del Fedro- o constituyan una especie de interpolación en el normal discurrir del discurso ético. Por un lado, Aristóteles sigue manteniendo en estos tres capítulos del libro décimo la poderosa incidencia del ser coincidental, manifestada en la necesidad de que el hombre contemplativo, por ser hombre, tiene de bienes externos, de alimento y cuidados. Y, por otro, resulta patente que la referencia a Dios es inesquivable en el conjunto de la filosofía del Estagirita, y no sólo en la Metafísica, sobre la cual la ética no se apoya explícitamente, pero de la que tampoco prescinde.

Lo cierto es que - no sin vacilaciones ni oscilaciones - la moral aristotélica culmina con una contemplación o pura teoría, como máxima praxis asequible a la persona humana, que si no garantiza para él la inmortalidad del alma intelectual, sí que constituye un modo específico de athanatítsein, de ponerse, aunque no sea más que por unos momentos, en contacto con lo que es indudablemente inmortal, el acto puro - el cual, por no poder ser de otra manera de como es (oudamôs allôs echein), por no actuar de un modo o de otro, ya que no es más que actuar, resulta absolutamente indestructible. Llegar, pues, al acto puro es alcanzar lo que rebasa nuestra vida de mortales y así, en cierto modo, llegar a la muerte. Y es que, como dice Inciarte, la consideración del fenómeno de la muerte ha sido desde siempre un incentivo para hacer filosofía. Porque Aristóteles considera que ni siquiera la filosofía práctica es un fenómeno puramente cultural, porque sus resultados no dependen

\footnotetext{
${ }^{53}$ Ética a Nicómaco, X, 7, 1177 b 32-35.

${ }^{54}$ Nussbaum: The Fragility of Goodness..., pp. 373-377.
} 
sin más del modo particular como un tipo u otro de humanidad razone. El Estagirita no es un relativista al modo sofístico. Piensa que la filosofía, en último término, trata de aquello que el hombre no puede cambiar. Ahora bien, lo único que el hombre no puede realmente cambiar es la muerte ${ }^{55}$.

Lo que no es más que su actuar, lo que no presupone nada, ninguna posibilidad, es lo originario, es lo imprevisible. Original es, dice Schelling, a propósito de la teología de Aristóteles, aquello en cuya posibilidad no se puede pensar ni creer antes de verlo realizado. En este sentido, el acto puro — que excluye toda derivación coincidental— es lo único realmente original, la originalidad misma; lo más admirable que quepa pensar, lo único admirable y lo único plenamente deleitable. Al ponernos en contacto con eso, al final del fatigoso camino de la ética, y sólo entonces, llegamos a tocar, aunque sólo sea por unos instantes, nuestra propia bienaventuranza; entonces, dice el mismo Schelling, alcanzamos no sólo la felicidad (la eudaimonía), sino la bienaventuranza (la makariótes); hemos rozado, más allá de la muerte, como en el arte, una vida distinta. Hemos de reconocer - $-\mathrm{y}$ tal es la limitación de este culmen de la ética aristotélica- que, si acaso, nosotros la conseguimos sólo en pocos instantes de nuestra vida; pero bien pudiera ser que, como decía Hölderlin, nuestra vida después de esos instantes, en lo que pueda tener de más valiosa, sea sólo un sueño de ellos, su recuerdo ${ }^{56}$.

De recuerdos y sueños está hecha la poética, cuya importancia para entender la ética de Aristóteles ha sido puesta de relieve por Ralph McInerny ${ }^{57}$, cuyas reflexiones me sirven de hilo conductor para concluir.

La vida y el alma del relato es la trama, el mythos, que es la lógica de los acontecimientos (logos tôn pragmatôn). Ahora bien, el ámbito de las acciones humanas, que es lo que la poética pretende imitar, es donde hallamos la felicidad o la desgracia, según hemos visto en nuestras anteriores consideraciones sobre la ética. Y estos accidentes morales compro-

\footnotetext{
${ }^{55}$ Fernando InCIARTE: Tiempo, sustancia, lenguaje. Ensayos de metafísica, Pamplona: Eunsa 2004, pp. 22-23.

${ }^{56} \mathrm{He}$ seguido a Inciarte en este punto. Cfr. Tiempo, sustancia, lenguaje..., pp. 30-31.

${ }^{57}$ Ralph MCINERnY: "La importancia de la Poética para entender la Ética de Aristóteles”, Anuario Filosófico, XX/1, 1987, pp. 85-93.
} 
meten la unidad de la acción que es imprescindible para que exista trama. Efectivamente, Aristóteles requiere que haya algún tipo de inevitabilidad en la secuencia: ya que aquello pasó, esto ocurrió. Tales accidentes producen el mayor efecto sobre la mente cuando ocurren inesperadamente y al mismo tiempo como consecuencia de otro accidente; así hay más maravilla en ellos que si hubiesen ocurrido por puro azar o por mera fortuna $^{58}$. ¿Significa esto que Aristóteles quiere eliminar de la narrativa eventos puramente casuales? En modo alguno. Pero tales coincidencias entran en la trama bajo condiciones muy rígidas.

Incluso los acontecimientos casuales parecen más maravillosos si hay en ellos alguna apariencia de designio, por decirlo de algún modo; como por ejemplo la estatua de Mitys en Argos que mata al autor de la muerte de Mitys al caerse sobre él mientras contempla un espectáculo público. Pensamos que accidentes como éste no carecen de significación. Por tanto, una trama de esta naturaleza es necesariamente más bella que otros tipos de trama ${ }^{59}$.

A semejanza de la ética, tampoco en la poética se deja al margen de la acción el ser coincidental. La moral no puede prescindir de él, porque aquello de lo que trata ha de referirlo "a los hechos y a la vida, y aceptarlo si está en armonía con los hechos, pero considerarlo como mera teoría si discrepa de ellos" ${ }^{60}$. Ahora bien, la ética no consigue, por así decirlo, insertar los accidentes morales en su propio discurso, porque no ocurren ni siempre ni la mayoría de las veces, y de suyo no cabe incluirlos en cadenas causales, ya que - si bien pueden ser causas impropias de otros acontecimientos - ellos mismos no tienen una causa determinada, pues proceden de la coincidencia de dos o más series causales independientes entre sí. En cambio, la poética sí que puede articular la narración de manera que los accidentes morales aparezcan prendidos en la trama. La manera como lo hace en cada caso es ficticia, pero no es ficticio en

\footnotetext{
${ }^{58}$ Cfr. Poética 1452 a 2-6.

${ }^{59}$ Poética 1452 a $7-11$.

${ }^{60}$ Ética a Nicómaco X, 8, 1179 a 20-23.
} 
absoluto el hecho de que tal tipo de eventos presenta una notable importancia en el curso de nuestras vidas y en los valores que en ellas se incorporan y se despliegan. De ahí que los relatos tengan de ordinario un valor más ejemplarizante que las argumentaciones éticas y que, en todo caso, deban precederlas o acompañarlas.

Al comenzar la lectura de la Ética a Nicómaco, la Ética a Eudemo, o incluso la Magna Moralia (que, sea o no obra directa del Estagirita, contiene indudable doctrina aristotélica); al empezar a leer esas obras, digo, uno tiene la impresión de que en ellas se va a hablar de cómo orientar la vida para que constituya un logro humano. Ahora bien, los actos relevantes para conseguir una vida moralmente positiva son las acciones conscientes y libres. Pero si tenemos en cuenta solamente ese tipo de acciones, quedan fuera de la vida multitud de cosas de las que, de un modo u otro, depende en buena parte el éxito de nuestra existencia. ¿Es este cuadro esquemático el que pretende transmitirnos Aristóteles?

La forma más rápida de corregir esta falsa interpretación es acudir a los propios relatos y, en especial, a las tragedias escritas en torno al siglo $\mathrm{V}$, de las que tan buen conocedor era Aristóteles. En ellas se contienen relatos de vidas humanas, en las que se incluye mucho más que la intención del agente. En todos los nudos de la trama comparecen accidentes y coincidencias que no son voluntarios ni intencionados. Tales acontecimientos, en los que se entreveran lo intencionado y lo no intencionado, son el meollo de las narraciones, y nos afectan profundamente porque llaman la atención hacia un rasgo inevitable de la acción humana.

Cada vez que actuamos podemos provocar más de lo que pretendemos, y no podemos escapar de esta situación, puesto que también podemos provocar lo que no pretendemos al inhibirnos de la acción. La vida humana es inevitablemente algo más que la realización de acciones morales, porque las acciones morales pueden acarrear resultados coincidentales no intencionados. Desde luego, no todos estos resultados son significativos; sólo cuando un efecto no intencionado (praeter intentionem) es un gran bien o un gran mal, hablamos de desgracia o de buena suerte. 
Lo que vale la pena subrayar de la Poética es que el efecto casual de una acción se admite en la trama sólo cuando parece adecuada su inclusión, como si fuera una consecuencia de actos intencionados. Parece sugerirse que, aunque nosotros sólo somos la causa per accidens de tales resultados, ya que no los pretendemos, hay no obstante una causa per se de ellos y por lo tanto esos resultados también son intencionados, pero no por nosotros mismos. La tragedia nos sugiere que incluso las consecuencias no intencionadas de nuestras acciones son parte de un todo inteligible, que nuestras vidas encierran un sentido que trasciende nuestras intenciones $^{61}$.

Al final de la Ética a Eudemo se lee esta inesperada sentencia: "Lo malo es aquello que por exceso o por defecto nos impide servir a Dios"62. A pesar de esta afirmación, la ética aristotélica sigue siendo más antropológica que teológica. Esta índole se confirma, por contraste, con unas palabras de Kierkegaard:

Lo que en la relación de hombre a hombre es admiración y envidia, en la relación de hombre a Dios es adoración y escándalo. La summa summarum de toda sabiduría humana es esta regla de oro o, mejor, dorada: ne quid nimis, nunca demasiado; demasiado o demasiado poco echa todo a perder. Entre hombre y hombre esto pasa por sabiduría y se paga con la admiración. El curso de esta moneda no oscila, la humanidad entera garantiza su valor. A veces, sin embargo, surge un genio que se eleva un tanto sobre el mercado cotidiano, y en seguida los prudentes le toman por majadero. El cristianismo da un paso gigantesco más allá: ne quid nimis, nunca es demasiado [...] Aquí empieza el cristianismo... y el escándalo.

\footnotetext{
${ }^{61}$ MCINERnY: "La importancia de la Poética... ”, p. 93.

${ }^{62}$ Ética a Eudemo, VIII, 3, 1249 b 19-20.
} 
Copyright of Tópicos. Revista de Filosofía is the property of Universidad Panamericana and its content may not be copied or emailed to multiple sites or posted to a listserv without the copyright holder's express written permission. However, users may print, download, or email articles for individual use. 